\title{
Benefits of Online Teaching for Face-to-Face Teaching at Historically Black Colleges and Universities
}

\author{
D’Nita Andrews Graham \\ Norfolk State University
}

\begin{abstract}
Technology and distance education are on the rise in community colleges, four-year institutions, Ivy League colleges, research institutions, and technical colleges. One of the most significant phenomena occurring in Historically Black Colleges and Universities (HBCUs) today is distance education. Academic leaders can better implement professional development plans to promote online programs if they understand faculty perceptions about teaching online. This phenomenological research paper presents the results of 12 experiences of higher education faculty members at an HBCU who transitioned from a face-to-face teaching modality to a distance education instructional delivery and subsequently returned to the face-to-face classroom
\end{abstract}

Keywords: online, face-to-face, HBCU, teaching experience, higher education, phenomenology

Andrews Graham, D. (2019). Benefits of online teaching for face-to-face teaching at historically black colleges and universities. Online Learning, 23(1), 144-163.

doi:10.24059/olj.v23i1.1435

\section{Benefits of Online Teaching for Face-to-Face Teaching at Historically Black Colleges and Universities}

There is minimal research that has examined how HBCU instructors who go from the classroom online tend to learn new approaches - techniques and philosophies - that they bring back to the classroom (in one way or another). Teaching online changes instructors' perceptions and their teaching practices when they return to the traditional classroom (Stone \& PerumeanChaney, 2011). Although higher education enrollments continue to decline, distance education enrollments continue to grow. Most higher education institutions provide some form of distance education. According to Allen and Seaman (2016), the number of students taking all of their courses online in 2014 was in excess of 2.8 million. The percentage of college students taking at least one online course is at an all-time high of 33.5\% (Allen \& Seaman, 2015).

Faculty members at institutions of higher education who started their careers in the traditional face-to-face classroom tend to change their pedagogical approaches for use in online teaching (Baran, Correia, \& Thompson, 2013; Duffy \& Kirkley, 2004; McDonald, 2002). As they gain experience in the online environment, they often turn the approach around, changing methods that benefit the online environment to improve and enhance their face-to-face teaching (Scagnoli, 
Buki, \& Johnson, 2009; Stone \& Perumean-Chaney, 2011). Therefore, it is important to consider and understand how college faculty who teach online perceive and describe their teaching practices and roles when they return to the traditional face-to-face classroom.

\section{Review of Related Literature}

In higher education institutions in the United States, enrollment in online courses continues to exceed growth in face-to-face courses (Allen \& Seaman, 2013, 2014, 2015). Online higher education faculty are reviewing their perceptions about the new culture of learning and teaching. This leads teachers to challenge their beliefs, judgments, interpretations, assumptions, and expectations (Coppola, Hiltz, \& Rotter, 2002; Lee \& Tsai, 2010). Kreber and Kanuka (2006) noted online teaching is different from face-to-face teaching; however, faculty who do not receive professional development have a habit of carrying face-to-face educational practices to online environments. Teachers tend to transfer face-to-face approaches learned from their professors while in college to the traditional classrooms they teach in as they develop their expertise (Kreber \& Kanuka, 2006).

According to Lokken and Mullins (2014), distance education administrators were asked to rank their greatest faculty challenges in the 2013 Instructional Technology Council (ITC) survey, and it was discovered that engaging in online pedagogy was a top concern for faculty. A major challenge is the necessary trial-and-error associated with the new technology features and functions (Moore \& Kearsley, 2012). Higher education faculty members are presented with the challenge of moving from Web 2.0 to Web 3.0, interactive media, streaming video, constant realtime networks and active learning communities. The paradigm shift is from center stage, application of knowledge, to coach, facilitator, or guide.

Sheridan (2006) and Van de Vord and Pogue (2012) suggest faculty are concerned that online instruction is more time-consuming than traditional face-to-face instruction. According to Van de Vord and Pogue (2012), online courses include more time in and out of the classroom for the instructor. Sheridan (2006) noted that faculty members who teach online courses spend more time preparing and administering their courses than traditional faculty members do. Higher education faculty indicate that continuous individual email communication is another challenging factor (Sword, 2012). Lloyd, Byrne, and McCoy (2012) reported one of the most highly ranked concerns of faculty was time commitment.

Many HBCU faculty members are just starting to transition their face-to-face courses to the teaching-at-a-distance environment and need hands-on experience. Lack of comfort and/or proficiency with technology tools may have more to do with a lack of time and less to do with opposition (Thormann \& Zimmerman, 2012). Building an online learning community; establishing netiquette; facilitating discussion, group work, and peer monitoring; and asserting the leadership role are crucial to effective communication and learning (Thormann \& Zimmerman, 2012).

\section{Theoretical Framework}

To understand HBCU faculty's attitudes and perceptions about education and instruction when they return to the face-to-face classroom, Mezirow's (1991) transformative learning theory was used. The transformative learning theory is based on the principle that personal experience is an important part of the learning process and that the adult learner's interpretation of the experience creates meaning, which leads to changes in their behavior, beliefs and assumptions, values, associations, feelings, and mindset. When transformative learning occurs, a learner may 
experience a paradigm shift that affects future experiences. With the rapid growth of online HBCUs, faculty members are re-examining their perceptions about the new culture of learning and teaching. This leads to teachers challenging their own beliefs, judgments, interpretations, assumptions, and expectations (Lee \& Tsai, 2010).

Transformative learning is a "process of examining, questioning, validating, and revising our perspectives" (Cranton, 2006, p. 23). The theory has been used in teacher education fields, such as teachers' application of new professional development program models (Kabacki, Odabasi, \& Kilicer, 2010), faculty members' use of technologies (Whitelaw, Sears, \& Campbell, 2004), and a teachers' learning of new concepts (Gilbert, 2003). Kabachi et al. (2010) described transformative learning as "a process in which adults change their views and habits - which they have gained as a result of their experience" (p. 266).

\section{Face-to-Face Versus Distance Education}

According to Baran, Correia, and Thompson (2013) distance education is different from the traditional classroom method and, therefore, its own pedagogies must be developed. In a faceto-face classroom, an instructor is assumed to be a lecturer, and in an online classroom, the instructor is considered a facilitator (Ryan, Scott, \& Walsh, 2010). A face-to-face classroom allows the instructor to be committed to just one block of time, provide structure and immediate feedback, teach with direct eye contact, and respond immediately to questions. An online classroom allows the instructor to organize online communication via emails, discussion boards, chats, and web conferencing. Researchers have reported "the teacher moves from being at the center of the interaction or the source of information to the "guide on the side" (Baran et al., 2013, p. 429). Additionally, instructors can establish learning activities, such as group work, through multiple rounds of communication and clarifications (Moore \& Kearsley, 2012). A paradigm shift occurs from student-centered learning to instructor-centered or lecture-centered approaches in teaching in a distance education environment (Simonson et al., 2012). Higher order thinking is often lacking in online learning, and this may be because instructors attempt to transfer traditional classroom practices to online courses (Baran et al., 2013). Research has demonstrated that "universities staying current with technological innovations results in improved online course development outcomes and satisfaction" (Fish \& Wickersham, 2010, p. 280). It is suggested that instructors remain current with advances in the field and to network with others who teach online courses within the same university or at other universities (Fish \& Wickersham, 2010).

\section{The Concern of Faculty Acceptance}

Institutions of higher learning generally set the pace for educational innovation; however, some higher education faculty members are not convinced of the value and legitimacy of distance education. The Pew Research Center conducted surveys on adults in the community and college presidents on the educational value of online courses. While $51 \%$ of college presidents suggested that online courses provide equal value compared with face-to face courses, just $29 \%$ of the public suggested online courses offer the same value (Parker, Lenhart, \& Moore, 2011). In 2003, chief academic officers reported that only $27.6 \%$ of their faculty members accepted the "value and legitimacy of online education" (Allen \& Seaman, 2015, p. 21). By 2007, the percentage had risen to $33.5 \%$, but in 2015 the rate was nearly back to where it had been in $2003: 28.0 \%$ of academic leaders said their faculty accepted the "value and legitimacy of online education" (Allen \& Seaman, 2015).

McCoy (2012) reported that one of the most highly ranked concerns of faculty was time commitment. At the same time, Allen and Seaman (2012) found that 58\% of 4,564 faculty members described themselves as filled more with fear than with excitement over the growth of 
online courses within higher education. On the other hand, academic technology administrators are extremely positive about the expansion of online learning, with $80 \%$ reporting they have more excitement than fear (Allen \& Seaman, 2012). As previously mentioned, when distance education administrators were asked to rank their greatest faculty challenges in the 2013 ITC survey, engaging in online pedagogy was a top concern (Lokken \& Mullins, 2014). Also previously noted is that a major challenge is the trial and error associated with the features and functions of the new technology (Moore \& Kearsley, 2012). The paradigm shift that has occurred removes teachers from center stage and the application of knowledge, to coach, facilitator, or guide.

\section{The Role of the Instructor}

With the growth of online education, the role of the instructor in higher education is changing. However, some higher education faculty members are resistant to teaching online because the demands are greater compared to face-to-face courses (Murphy, Levant, Hall, \& Glueckauf, 2007). The roles of online instructors may be more complex than those of traditional instructors (Baran, Correia, \& Thompson, 2013). Some higher education faculty members are resistant to teaching online because the demands are greater compared to traditional face-to-face courses (Murphy, Levant, Hall, \& Glueckauf, 2007). According to Baran et al. (2013), distance education is different from the traditional classroom method and, therefore, its own pedagogies must be developed.

\section{Benefits of Online Teaching for Face-to-Face Teaching}

As McDonald (2002) noted, not only does teaching at a distance often prompt a closer examination of teaching practices, but online teaching has the potential to enhance face-to-face teaching. McDonald (2002) suggested that "in addition to reaching learners at a distance, distance education formats are increasingly being used to enrich, improve, and expand face-to-face instruction, thus resulting in a 'convergence' of educational practices" (p. 12). Best practices applied in the online classroom can be transferred to the face-to-face classroom to improve student learning in any environment (Burgess, 2015). Some of the best practices Burgess returned to the face-to-face classroom with were online discussion boards, course content videos, ecommunication, and web conferencing tools. In her face-to-face classroom, she uploaded material, provided PowerPoint slides, and shared feedback through a learning management system (LMS). Upon her return to the face-to-face classroom, she incorporated online discussion to improve learning by allowing students to reflect on readings, offer productive starting points for class conversations, and articulate their thoughts prior to group discussions. One successful component Burgess used in her online class and transferred to her face-to-face class was a weekly checklist. The most valuable and effective transferable skill Burgess noted was web conferencing because of the flexibility it provided for both the student and the instructor. In her face-to-face course, she now offers the option to meet in person, online, or both.

Scagnoli, Buki, and Johnson (2009) conducted a qualitative cross-case analysis of studies of the influence of online teaching on classroom teaching practices. They examined several articles that were cross-analyzed by categories, including transfer of pedagogical strategies back to the classroom, increased readiness to integrate technology in the classroom, and openness to alternative ways of interaction. Scagnoli et al. (2009) found that instructors come back to the classroom with new pedagogical strategies for instruction and online presentations, the use of audio and video files, discussion forums and chat sessions, and submission of assignments via an LMS. Many face-to-face instructors benefit from using an LMS by uploading and updating course material. Faculty realize that some of the same approaches used in online classes can be used to engage students' learning in face-to-face classes. Scagnoli et al. (2009) also suggested that faculty 
teaching at a distance returned to the classroom eager to integrate technology in their face-to-face course. When instructors step out of their comfort zone of the face-to-face classroom to participate in teaching at a distance, they obtain new knowledge and proficiencies (Cho \& Berge, 2002). In their study, instructors who had taught online were more conscious of their teacher roles and teaching strategies. Some instructors became more acquainted with the use of technology, new pedagogical techniques, unique forms of accountability, and collaborative learning practices.

Fetzner (2003) offered lessons learned about transferring teaching practices from distance education to face-to-face classrooms with the Monroe Model framework. The model addresses how faculty bring lessons learned from an online environment to a face-to-face environment. When higher education faculty experience positive outcomes when teaching online, it promotes a change in opinions, attitudes, perceptions, and understanding of distance education. Stone and Perumean-Chaney (2011) offered lessons learned with the development and delivery of an online statistics course. The course was designed to be delivered in weekly modules, and each module began with an overview. The module overview was concise, organized, and included specific goaldirected activities, with students knowing what each module covered. When the format of using weekly modules for the presentation of material and the assignment of homework was brought back into the traditional classroom, Stone and Perumean-Chaney (2011) found that student confusion was minimized, leaving more time for additional activities to enhance student learning. Additionally, Stone and Perumean-Chaney (2011) discovered that when instructors returned to the face-to-face statistics classroom, they had adopted new technologies, created new ways for students to submit their work, learned new approaches for enhancing student engagement, and improved student learning.

\section{Method}

The phenomenological approach for this study was selected to understand common and/or shared experiences (Creswell, 2013). The goal of this research was to explore the experiences of higher education faculty members at an HBCU who transition from the online classroom to the face-to-face classroom. The central research question of this study was this: How does teaching at a distance affect the attitudes, perspectives, and practices of higher education faculty when they return to face-to-face teaching? Additionally, three subquestions guided this study:

1. How are instructors' perceptions of their role and their teaching practices altered when they return to instruction in a face-to-face classroom?

2. What communication strategies do instructors transfer from online to face-to-face teaching?

3. What changes in face-to-face instruction can be attributed to the experience of online teaching?

\section{Sampling}

The participants for the study were selected using purposeful sampling of volunteers with face-to-face and online teaching experience, across different disciplines. Participants were fulltime and adjunct faculty members who were engaged in the development and teaching of online courses at a four-year Historically Black University in Virginia. The university's 2017 Fact Book shows a headcount of 5,305; 83\% of its students are Black, 5.1\% are White, and 11.9\% are classified as other (includes international and unknown). Sixty-four per cent of the students are female, and $36 \%$ are male. In addition to serving a high proportion of students of color, many 
students are first-generation college students. The university offers 178 online courses. Participants were selected from the 112 faculty members who were certified to teach online courses. The university offers seven undergraduate online degree programs and five graduate online degree programs. The award of the Quality Standards Certification from the United States Distance Learning Association is a solid accomplishment for the university distance education programs, its faculty, staff, and students.

\section{Data Collection}

Data for the project was collected in spring 2017. IRB approval was obtained prior to data collection. A semistructured interview protocol (Appendix A) was followed to uncover the underlying themes related to this phenomenological study (Merriam, 2009). A subject-matter expert in the field of distance education was asked to review the protocols to verify content validity. Two nonparticipating faculty members were asked to pilot test the questions for feedback and validity prior to use.

The interview consisted of open-ended questions with prompts to elicit responses from all participants. A digital recorder was used to collect data, and field notes were taken. It was also important to maintain a balance between descriptive notes and reflective notes, such as hunches, impressions, and feelings (Groenewald, 2004). The memos (or field notes) were dated so they could be later correlated with the data (Miles \& Huberman, 1984). Three types of field notes were utilized: (a) theoretical notes (TN) - attempts to derive meaning as the researcher thinks or reflects on experiences; (b) methodological notes (MN) - reminders, instructions, or critiques on the process; and (c) analytical memos (AM) - end-of-a-field-day summaries or progress reviews.

There were nine demographic questions and nine questions about the participants' perspective on education and instruction when they returned to the face-to-face classroom after teaching online. The interview lasted approximately 60 minutes. An initial precoding process was used to identify repetitive terms, which was followed by reviewing, analyzing, and classifying the themes according to the appropriate research questions (Saldana, 2013).

\section{Data Analysis}

This study investigated the experiences of 12 participants. According to Doyle (2006), when determining the sample size for a qualitative study, it is more important to identify participants who are more knowledgeable than to include a large population. A smaller sample size with a rigorous analysis was sufficient because the study was of an exploratory nature (Daniel, 2012). Saturation is the point in the data collection process where the information becomes redundant (Bogdan \& Biklen, 2007, p. 69). Guest, Bunce, and Johnson (2006) discovered that saturation usually occurs within the first 12 participants. After 12 interviews, the answers to the questions become redundant, and no new data are offered (Guest, Bunce, \& Johnson, 2006).

The precoding process started with color-coding identified words and phrases that were "worthy of attention" (Saldana, 2013, p.19). Then open coding, also known as initial coding, was utilized to break down the data. The codes and code definition were determined and organized from selected terms, words, and phrases for comparison and contrast (Corbin \& Strauss, 1998). The categories that began to emerge were reexamined, and a set of themes emerged. These themes were reviewed, analyzed, and classified according to the appropriate research questions with which they were associated.

The descriptive narratives, gathered during individual interviews, were essential, as they provided detailed phenomenological descriptions of the transition experience of HBCU faculty members. The common experiences, explaining the consistency of responses for each participant 
and the number of times the responses appeared in the transcriptions, were tallied. Once the common experiences were determined, all the transcriptions were studied to determine the number of frequency responses related to each theme. Then, the number of times each common experience appeared within the transcriptions was totaled.

To establish trustworthiness, triangulation was used. Triangulation is using more than one method to collect data on the same topic to verify the findings (Yin, 2014). This is a way of ensuring the validity of research. The study used face-to-face interviews, field notes, interview transcripts, and recordings to increase the study's credibility and help ensure that the findings were accurate (Creswell, 2012).

Participants were able to view the transcribed interviews and the established themes. This allowed participants the opportunity to correct any misunderstanding to ensure that the information accurately described their viewpoints and to share their opinions on the accuracy of the findings (Creswell, 2012).

\section{Results}

Based on the results relative to all four research questions, three themes emerged from this study: (a) faculty roles and teaching practices, (b) faculty communication strategies, and (c) faculty changes in instruction. There were similarities among the experiences of the participants in relation to their transition from online teaching to face-to-face teaching. In their transition, the majority of the participants noted their teaching role changed to more of a facilitator since teaching online. All the participants mentioned that they changed from teaching in an instructor-focused environment to a learner-focused environment.

\section{Results for Central Research Question}

The responses to the central research question served as a foundation in understanding how teaching at a distance affects the attitudes, perspectives, and practices of higher education faculty when they return to face-to-face teaching. All of the participants specified that teaching online assisted them in thinking differently about their face-to-face teaching. The majority of the participants mentioned that they improved their ability to interact and respond to questions. Some mentioned that teaching online has increased their awareness of students' needs and methods to create engaging activities:

Teaching online changed my attitude and perspectives when returning to face-to-face teaching because I can tell by students' responses, expressions when they do not understand something right away. I can also see when the material is not interesting. This allows me to improve what material is essential and provide activities that are engaging and enhance student learning. (Participant C)

My interaction in my face-to-face class is greater now due to my online experience. I really feel like students are getting double for their money because they are getting the face-toface experience and they are getting the online experience as well. They have immediate access to me in class and they have access to all the resources. (Participant F)

When you are teaching online, you do not have access to non-verbal cues, expressions, and gestures; therefore, you need to be extra careful in communicating. Communication must be clear. You need to be very inviting in terms of feedback from students. (Participant G) 
One instructor noted that it is easier to teach face-to-face after teaching online, while another instructor disagreed and faced challenges when returning to the face-to-face classroom:

It is so much easier to teach face-to-face after teaching online because I have mirrored my face-to-face class after my online course. My attitude and perspectives have changed since teaching online and returning to the face-to-face class. I am able to share the online resources with the face-to-face class. I use some of the same methods and I have structured my face-to-face course in the same format as my online course. (Participant I)

My attitude and perspective after teaching at a distance and transitioning to the face-toface classroom was that I struggled with lecture present. I thought I could just jump back into the classroom but it was a huge challenge for me. I was trying to use the same material but I had to go back and completely redesign a lot of my material to be more entertaining. I felt like I had to entertain the students more in a face-to-face class than I do in an online class. Online students are much more engaged and face-to-face students still want to be spoon-fed. I increased my level of communication using both asynchronous and synchronous tools within my LMS, which allows me to almost connect with students $24 / 7$, not practical but available. I have realized teaching online and face-to-face that online students are much more engaged and require feedback more often. (Participant $\mathrm{H}$ )

Finally, teaching online has helped the participants to integrate more technology into face-to-face classrooms:

I like the fact of using the technology because even in my face-to-face class I use Blackboard, Collaborate Ultra, and Adobe Connect. Many of my students are nontraditional students who work and have other responsibilities and are not able to come to class. It has been great to be able to speak with them virtually. I have PowerPoints and videos that I use for my face-to-face class. I like the fact that my face-to-face students submit their work online also because this keeps clutter away from my office. Blackboard reminds them when the work is due; I know when the work is due and who has submitted. It just makes life easier for the student and the instructor. (Participant B)

Since teaching online, I use more technology in my face-to-face class. I also use the document camera to capture 3D object and/or 2D images, create more discussion, interaction, and capture students' attention. Effective technology integration changes the dynamics of the classroom and promote student-centered. Students not only become engaged, but they also begin to take more control over their own learning. (Participant F)

I have taught face-to-face and fully online classes within the same semester and I have noticed that upon returning to my face-to-face classes from my online experience was the fact that I realized that I began to use more technology. For example, for my face-to-face class I would only use hardcopy gradebooks to organize the course. This was not beneficial to the students because they were not able to see immediate results of their scores; therefore, I decided to use online grading. I also integrated Blackboard mobile, audio, and video in my face-to-face course. (Participant K)

\section{Results for Research Subquestion 1}

Subquestion 1 asked, How are instructors' perceptions of their role and their teaching practices altered when they returned to instruction in a face-to-face classroom? Faculty members indicated that, when they returned to the face-to-face classroom, they moved from being at the center of the interaction or the source of information to the "guide on the side." They noted they 
became less of a lecturer and more of a facilitator, which was the highest ranked role identified in this study. The second-highest-ranked role identified was resource provider.

Two of the participants described their role as a manager/administrator because they supervised and moderated discussions, organized, planned, evaluated assignments, and maintained student records. This aligns with the findings of Baran et al. (2013) and Guasch et al. (2010), who suggested that the administrative manager role comprises carrying out the pedagogical tasks related with course management, including establishing rules and regulations, student registration, and recordkeeping:

I can honestly say I did lecture more, but now I am more of a facilitator and I have also altered my role with being a resource provider because my face-to-face students have access to the material 24/7. This is beneficial to the face-to-face students because they do not have to wait until the next class or office hours, they can simply go online and obtain what is required and if they need to contact me I am only an email or Collaborate [Ultra] away. Before I started teaching online I was definitely more of a lecturer and my courses were more teacher-centered but I have altered my role and teaching practices to be a One Stop Shop. (Participant B)

My courses were designed around more of me attempting to get students to understand the material. Now I am more of a manager and administrator because I plan, organize, supervise, and provide all the resources that are necessary and required for them to be successful and I observe their progress. (Participant C)

I have always desired to become more of a facilitator. I would say that online teaching moved me in the direction of being more multimodal in my approach. Working to become a facilitator and placing more of the ownership of the learning process on the student. The way I have structured my face-to-face course has allowed me to create a more studentcentered environment. This has been great for me. The students were kind of like, "what is this?" I am responsible. I feel like I am still a relatively late adopter to some of the more innovative things I can do with the resources that we have at our disposal, but I definitely see myself as managing the learning process. (Participant $\mathrm{J}$ )

A paradigm shift occurred within the participants' teaching practices. All 12 participants reported they changed from teaching in an instructor-centered or lecture-centered environment to a student-centered learning environment. Six of the participants explained that the differences between teaching online and of face-to-face teaching included direct eye contact, seeing students' nonverbal cues, provide immediate feedback, responding directly to questions, and assisting with problems. Eight of the participants indicated teaching online has made them more aware of the needs of their students and how to engage them to understand the content.

\section{Results for Research Subquestion 2}

Subquestion 2 asked, What communication strategies do instructors transfer from online to face-to-face teaching? Eight of the participants indicate they utilized both synchronous and asynchronous formats. Four of the participants indicated that they used asynchronous formats, such as discussion forums, blogs, and wikis. All 12 participants stated they used email to communicate with students. Nine of the 12 participants also stated they used Collaborate Ultra as a communication strategy that was transferred from online to the face-to-face classroom. They discovered that they were not limited to using telephone calls and emails when they returned to the face-to-face classroom. These participants explained that they now allow their face-to-face 
students to view prerecorded lectures, access material online, and collaborate with them and their peers on their own schedule:

When my father-in-law passed, I was out of town and I could not meet my face-to-face class in the physical classroom, but we still had class virtually. I used Blackboard Collaborate for my virtual classroom meeting. Therefore, there was no class time missed or needed to be made up due to the virtual meetings that we were able to have. I had the ability to communicate and engage with my students in real-time discussion. They were able to view the content and I recorded the presentation and posted for students who did not show for virtual face-to-face class. I also had virtual office hours utilizing Collaborate Ultra. (Participant B)

I transferred from online to face-to-face teaching was using Collaborate Ultra with my face-to-face students. If I need to talk with them over the weekend, I can leave Ultra open on my computer and it just dings at me when they show up. Whenever I am unable to come to campus to hold regular class periods or when the campus is closed due to bad weather or an emergency, I use Ultra. In addition, I expanded my office hours by scheduling online time with students to answer questions about assignments or the course in general, to provide instruction, or to give feedback. Collaborate Ultra not only provides online students with a communication medium anywhere in the world but also face-to-face students as well. In my opinion, web conferencing is the ideal tool to bridge the communication gap between face-to-face students and online students. (Participant I)

The communication strategies that I transferred from online to face-to-face are announcements, emails, and Collaborate Ultra. I am still learning all the bells and whistles of Ultra but I really like the tools and my students seem to enjoy it also. (Participant D)

Students like Collaborate Ultra because they can use their mobile devices, especially their phones. It's like FaceTime for the Apple users. (Participant A)

The participant who used Collaborate Ultra had a positive experience. Findings indicated that Collaborate Ultra is efficient in terms of promoting flexibility, interaction, learning community, and engagement between student and instructor. Collaborate Ultra made a difference by providing communications comparable to face-to-face classes. The video feature in particular makes synchronous discussions possible, enabling the instructor to go beyond asynchronous online discussions. Students were able to see the instructor and hear him or her through video and audio. This was important to simulate face-to-face class experiences and provide various interaction opportunities between the instructor and the student.

All 12 of the participants specified they transferred video material from online to the faceto-face classroom. Seven of the 12 participants said they also transferred audio material from their online to face-to-face classroom. Seven of the participants mentioned another communication strategy that helped increase and enhance their face-to-face classroom was the online discussion board:

Prior to teaching online, I made very little use of discussion boards for my face-to-face classes. I was more familiar with reflection papers. Having seen the benefits of online discussion boards, I began to use them for my face-to-face class. These discussions have helped to enrich my classroom discussions. They have improved learning by allowing students to reflect on assigned readings, offer conversation, and assist them with articulating their thoughts prior to the discussion. The students actively participate without 
feeling the overwhelming discomfort they may feel with many eyes on them in a face-toface class. (Participant L)

The discussion forum was one of the most popular features that transferred from my online teaching to face-to-face teaching. The discussion forum helped enhanced students to talk more with me. Typically, I would provide some guiding questions to foster a habit of critical thinking, reflection and articulating online. The discussion became studentcentered and more students participated and shared their ideas and experiences, more than they did in class discussion. (Participant G)

I use the discussion board to continue an in-class discussion. I have discovered that ... some students are not confident and prefer not to speak in class but are willing to contribute to the discussion boards. It also allows students time to reflect on their thoughts before contributing, practice their writing skills, and offer peer-learning opportunities. The discussion board has been a positive experience for both my face-to-face students and me. It has led to engaging and productive discussions. (Participant I)

Five of the participants indicated that the discussion board did not transfer from their online course to their face-to-face course:

I prefer for my students to talk to me face-to-face and not hide behind a screen. My students were not engaged in a true, back-and-forth dialogue but just typed something for contributing purposes. It seemed like it was more of an exchange of information than a true discussion. (Participant E)

Online discussion decreases social interaction. The discussions can become complicated and students go off-topic and wish they could retract their threads and then they become more argumentative instead of collaborative. (Participant D)

The discussion forums were not beneficial in my face-to-face class because I had to use a lot of time moderating and monitoring students' inappropriate postings. Some students wanted to dominate the conversation and this caused negative postings. This reduced students' motivation with the online discussion forum and in-class interaction with one another. (Participant C)

\section{Results for Research Subquestion 3}

Subquestion 3 asked, What changes in face-to-face instruction can be attributed to the experience of online teaching? Ten participants reported having implemented online tests and quizzes in their face-to-face instruction. One of the most common strategies to be incorporated into classroom instruction was the use of technology. All participants indicated that since teaching online, they have incorporated some type of technology into their face-to-face classroom. Most of the participants changed their perceptions regarding the role of technology. Participant A changed from viewing technology as a technical tool for supporting teaching to a view of technology as a tool for enhancing learning:

Technology has transformed the teaching and learning experience in my classroom. My students are able to access the information quicker and easier than ever before. Since I have started to integrate technology, the traditional passive learning model is gone. I have become the facilitator, coach, adviser, and encourager with utilizing technology in my faceto-face classroom. I do not think you should just use technology because you can or let technology take over your class. You must understand how to use it, train students in using it, and learn what benefits the technology brings to your class. (Participant B) 
Technology has totally changed the dynamics of how I teach. I am learning how to teach with emerging technologies (computers, smartphones, iPads, Google cardboards, smart boards, tablets, digital cameras, virtual reality headsets) while my students are using advanced technology to shape how they learn. I have embraced and integrated technology in my online and face-to-face classroom. My goal is to set my students up for a successful life outside of the classroom by developing technological skills so they will be prepared to enter the workforce once they complete their degree. (Participant G)

It is one thing to use technology, it is another thing to know how to use technology and use it effectively and responsibly. When you use it effectively, you can assist students in preparing for their future careers. I integrate technology into my face-to-face class since transitioning from online teaching to connect with students of all learning styles and to help develop students' digital citizenship skills. It has helped my students in my face-to-face class to be more engaged, creative, and connected. (Participant J)

Several participants found that technology changed their practices in teaching and learning because the classroom became more student centered rather than teacher centered. All participants reported that, since returning to the face-to-face classroom, they have continued to use Blackboard, PowerPoints, and multimedia. Four of the participants indicated they used proctored assessments for their face-to-face classrooms since teaching online. All participants indicated they used Respondus LockDown Monitor when requiring proctored assessments:

Online proctoring is easier than face-to-face proctoring because she is the only instructor in the room and it is harder to catch students cheating. She also noted that she wanted her students to be familiar with and knowledgeable of the online proctoring process. (Participant F)

Many high-tech companies offer certification exams and do not always require applicants to travel to a brick-and-mortar test center but instead utilize online proctoring. Being familiar with the online proctoring process could be a benefit for the student, helping reduce the fear of new technology. (Participant $\mathrm{G}$ )

It was reported by two participants that online proctoring for their face-to-face course was beneficial when they had to attend conferences or miss a class. Six of the participants reported they use rubrics to make expectations and criteria explicit and to facilitate feedback and selfassessment. Nine of the participants indicated that they have incorporated electronic resources into their face-to-face teaching instruction since teaching online.

Most participants had an appreciation of using technology in their online course, and it extended to their traditional face-to-face course. Upon their return to the face-to-face classroom, they provided students with new, authentic, and meaningful learning experiences through the implementation and integration of emerging technologies. By providing video and audio content, students are able to learn at their own pace and to go back and relearn material whenever they want. This could be especially important for students with learning disabilities. All participants benefited from using an LMS by uploading files, updating course material, submitting grades, and providing feedback.

All participants recognized the changes in face-to-face instruction that could be attributed to the experience of online teaching, as most of the same methods used in online classes can benefit the face-to-face classroom. Many participants indicated that their online courses are designed to utilize weekly modules, and they transferred this to the face-to-face classroom. This format has reduced confusion. It was reported that, due to the format of weekly modules, 
instructors were able to provide more clear and concise expectations, provide additional practice samples, and reinforce the material while maintaining the class schedule. It was mentioned that the face-to-face course is more organized and, if more time was needed for something, it could be covered online via discussion forum or web conferencing. For all of the participants, the experience of teaching online improved teaching practices when they returned to face-to-face teaching.

\section{Discussion}

This study investigated the experiences of 12 participants: three professors, four associate professors, one assistant professor, three instructors, and one adjunct. The data were thematically analyzed and interpreted as a means of explaining the findings. Three themes were identified: (a) faculty roles and teaching practices, (b) faculty communication strategies, and (c) faculty changes in instructions. The participants in this study recognized their transition from lecturer to facilitator, knowledge dispenser to resource provider, and authority figure to advisor. The transforming roles of the participants varied. They described themselves as facilitator, guide on the side, coach, cheerleader, content provider, and course designer. The four categories that described the faculty roles were facilitator, resource provider, advisor, and manager/administrator. The participants modified their teaching practices from a traditional teacher-centered to a student-centered environment. The study indicated that since participants have transitioned from online teaching to face-to-face teaching they have reduced their traditional instruction of the usual lecture-centric assignments and assessment model to peer-based learning techniques and online assignments that force independent thinking and information gathering. The participants noted that facilitating and monitoring discussion, netiquette, peer review, and the manager/administrator role are essential to effective communication.

As reported by Burgess (2015) and Simonson et al. (2014) successful interactive learning experiences that work in one learning environment may be adaptable for another one. In the asynchronous environment, the teaching strategies promote interaction, student engagement, and active learning. Burgess and Simonson et al. (2014) agreed that discussion forums can keep the learner active, and enhance students' interaction with the instructor, other learners, and content. The participants reported that online courses offer more flexibility, access, and convenience, and they have offered these same advantages to their face-to-face students. Since teaching online, participants noted that they incorporated narrative lectures, audio and video files, electronic resources, wikis, online tests and quizzes, web conferencing, and online discussion forums. This study indicated that synchronous and asynchronous web-conferencing sessions can be beneficial in a face-to-face environment. The participants integrated videos into the LMS to enhance the teaching and learning process. The study's results are also consistent with several meta-analyses that have shown that technology can enhance learning (Schmid et al., 2014), and multiple studies have shown that video, specifically, can be a highly effective educational tool (Hsin \& Cigas, 2013; Kay, 2012; Rackaway, 2012).

\section{Practice}

A number of implications related to practice emerged because of this research. The major implication includes the need for continuous training for HBCU faculty members to enhance their online teaching. Studies of online teaching have established that online instructors often rely on their past teaching experience when preparing to teach online (Choi \& Park, 2006; Conceicao, 2006; Conrad, 2004). Faculty members whose experience has been confined to the traditional classroom cannot be expected to know how to design and deliver an effective online course (Palloff 
\& Pratt, 2001). Providing professional development to faculty members can help them in getting started and support their ongoing work in online teaching (Palloff \& Pratt, 2001). After completion of initial training, faculty should continue receiving professional development to become aware of emerging technologies and stay current on effective educational practices (Allen \& Seaman, 2016). This study's findings confirm previous research (McQuiggan, 2012) indicating that faculty members who had the opportunity to receive professional development, collaborate with experienced online colleagues, review examples of online courses, and identify their perceptions about changing their face-to-face teaching practices were effective in integrating these new emerging pedagogical strategies.

\section{Theory}

The evidence of transformative learning that occurred for the 12 faculty participants in this study suggests recommendations for improving instructional practices for teaching in the face-toface classroom after transitioning from online teaching. The theoretical foundation of the study was the theory of transformative learning. Faculty members' experiences and perceptions of online teaching, critical reflection on these experiences, and disorienting dilemmas are key in transformative learning. The participants noted that they were aware that their efforts to create engaging activities in their classrooms presented disorienting dilemmas. Additionally, all of the participants described an occurrence of a transformation in their teaching roles. Participants of this study noted that higher education faculty members should reassess the assumptions of their formative years that have often resulted in biased views of reality.

\section{Limitations and Recommendation}

The purpose of this study was to describe faculty members' perceptions at only one HBCU institution. The results of this study offer insights to peer institutions with similar backgrounds but may not be generalizable to a larger population (Yin, 2014). A larger sample and different types of higher education institutions could have strengthened the results. Research efforts across peer institutions may advance the study by sharing best practices. The participants in this study were faculty members with several years of online teaching experience. Utilizing the transformative learning theory, future research could consider examining the learning experiences of faculty members who are new to online teaching and learning.

It is useful to consider the lived experiences of present participants in online education courses and utilize their perspectives, feedback, and recommendations to assist in meeting the needs of future online instructors to improve the teaching and learning process in both the online and face-to-face classrooms. This study indicated that faculty hold diverse perspectives on transitioning from online teaching to face-to-face teaching, including different advantages and disadvantages, successes and challenges, improvements and limits, and suggestions and recommendations for transitioning from teaching online to teaching in the face-to-face classroom effectively. This study provided insights that may assist in the transfer of successful online pedagogical strategies that can benefit the traditional face-to-face classroom. Institutions should also support teaching efforts and provide the necessary support and professional development on the LMS and other technologies. It would be beneficial for all stakeholders in education to join efforts and build bridges by sharing success stories and best practices to enhance the educational outcomes for all instructors, students, and higher education institutions. 


\section{Acknowledgement}

This research was financed by a National Science Foundation-supported project, Expanding the Network of STEM Scholars through the ADVANCE Women of Color Summer Writing Retreat. Award Number 1463991. 


\section{References}

Allen, I. E., \& Seaman, J. (2014). Grade change: Tracking online education in the United States. Retrieved from http://www.onlinelearningsurvey.com/reports/gradechange.pdf

Allen, I. E., \& Seaman, J. (2015). Grade level: Tracking online education in the United States. Retrieved from http://www.onlinelearningsurvey.com/reports/gradelevel.pdf

Allen, I. E., \& Seaman, J., Lederman, D., \& Jaschik, S. (2012). Conflicted: Faculty and online education. Retrieved from https://www.insidehighered.com/sites/default/server_files/files/IHE-BSRG-Conflict.pdf

Baran, E., Correia, A. P., \& Thompson, A. (2013). Tracing successful online teaching in higher education: Voices of exemplary online teachers. Teachers College Record, 115(3), 1-41.

Burgess, O. (2015). Cyborg teaching: The transferable benefits of teaching online for the face-toface classroom. Journal of Online Learning and Teaching, 11(1), 136-144.

Cho, K., \& Berge, Z. L. (2002). Overcoming barriers to distance training and education. USDLA Journal, 16.

Conceicao, S. (2006). Faculty lived experiences in the online environment. Adult Education Quarterly, 57, 26-45.

Conrad, D. (2004). University instructors' reflections on their first online teaching experience. Journal of Asynchronous Learning Networks, 8(2), 31-44.

Coppola, N., Hiltz, S., \& Rotter, N. (2002). Becoming a virtual professor: Pedagogical roles and asynchronous learning networks. Journal of Management Information Systems, 18(4), 169-189.

Cranton, P. (2006). Understanding and promoting transformative learning: A guide for educators of adults. San Francisco, CA: Jossey-Bass.

Creswell, J. W. (2012). Educational research: Planning, conducting, and evaluating quantitative and qualitative research (4th ed.). Upper Saddle River, NJ: Pearson.

Creswell, J. W. (2013). Qualitative inquiry \& research design: Choosing among five approaches. Los Angeles, CA: Sage.

Creswell, J. W. (2014). Research design: Qualitative, quantitative, and mixed methods approaches (4th ed.). Thousand Oaks, CA: Sage.

Daniel, J. (2012). Sampling essentials: Practical guidelines for making sampling choices. Thousand Oaks, CA: Sage.

Duffy, T. M., \& Kirkley, J. R. (2004). Introduction: Theory and practice in distance education Learner-centered theory and practice in distance education. In M. G. Moore \& W. G. Anderson (Eds.), Handbook of distance education (pp. 3-13). Mahwah, NJ: Erlbaum.

Fetzner, M. (2003). Institutional support for online faculty: Expanding the model. In J. Bourne \& J. C. Moore (Eds.), Elements of quality in online education: Practice and direction (pp. 229-243). Needham, MA: Sloan-C.

Fish, W., \& Wickersham, L. (2010). Best practices for online instructors. Quarterly Review of Distance Education, 10(3), 279-284.

Gilbert, J. L. (2003, April). Transformative learning process of one teacher. Paper presented at the American Educational Research Association Conference, Chicago, IL.

Guasch, T., Alvarez, I., \& Espasa, A. (2010). University teacher competencies in a virtual teaching/learning environment: Analysis of a teacher training experience. Teaching and Teacher Education, 26, 199-206.

Guest, G., Bunce, A., \& Johnson, L. (2006). How many interviews are enough? An experiment with data saturation and variability. Field Methods, 18(1), 59-82. 
Hsin, W. J., \& Cigas, J. (2013). Short videos improve student learning in online education. Journal of Computing Sciences in Colleges, 28, 253-259.

Kay, R. H. (2012). Exploring the use of video podcasts in education: A comprehensive review of the literature. Computers in Human Behavior, 28, 820-831.

Lee, M.-H., \& Tsai, C.-C. (2010). Exploring teachers' perceived self-efficacy and technological pedagogical content knowledge with respect to educational use of the World Wide Web. Instructional Science, 38(1), 1-21.

Lloyd, S. A., Byrne, M. M., \& McCoy, T. S. (2012). Faculty perceived barriers of online education. Journal of Online Learning and Teaching, 8(1), 1-12.

Lokken, F., \& Mullins, C. (2014). Trends in elearning: Tracking the impact of elearning at community colleges. Retrieved from http://www.itcnetwork.org/membership/itc-distanceeducation-survey-results.html

McDonald, J. (2002). Is as good as face-to-face as good as it gets? Journal of Asynchronous Learning Networks, 6(2), 10-23.

McQuiggan, C. A. (2012, June). Teaching with new eyes: Transformative faculty professional development for online teaching. Paper presented at the Adult Education Research Conference, Harrisburg, PA.

Merriam, S. (2009). Qualitative research: A guide to design and implementation. San Francisco, CA: Jossey-Bass.

Mezirow, J. (1991). Transformative dimensions in adult learning. San Francisco, CA: JosseyBass.

Miles, M. B., \& Huberman, A. M. (1984). Qualitative data analysis: A sourcebook of new methods. Newbury Park, CA: Sage.

Moore, M. G., \& Kearsley, G. (2012). Distance education: A systematic view of online learning (3rd ed.). Belmont, VA: Wadsworth Cengage Learning.

Murphy, M. J., Levant, R. F., Hall, J. E., \& Glueckauf, R. L. (2007). Distance education in professional training in psychology. Professional Psychology, 38(1), 97-103.

Newman, M. (1994). Responses to understanding transformation theory. Adult Education Quarterly, 44(4), 236-242.

Parker, K., Lenhart, A., \& Moore, K. (2001). The digital revolution and higher education: College presidents, public differ on value of online learning. Education Journal, 202, 29.

Rackaway, C. (2012). Video killed the textbook star? Use of multimedia supplements to enhance student learning. Journal of Political Science Education, 8, 189-200.

Ryan, J., Scott, A., \& Walsh, M. (2010). Pedagogy in the multimodal classroom: An analysis of the challenges and opportunities for teachers. Teachers \& Teaching, 16(4), 477-489.

Scagnoli, N. I., Buki, L. P., \& Johnson, S. D. (2009). The influence of online teaching on faceto-face teaching practices. Journal of Asynchronous Learning Networks, 13(2), 115-128.

Schmid, R. F., Bernard, R. M., Borokhovski, E., Tamim, R. M., Abrami, P. C., Surkes, M. A., ... Woods, J. (2014). The effects of technology use in postsecondary education: A metaanalysis of classroom applications. Computers \& Education, 72, 271-291.

Sheridan, R. (2006). Reducing the online instructor's workload. EDUCAUSE Quarterly, 29(3), 65-67.

Simonson, M., Smaldino, S. E., Albright, M. J., \& Zvacek, S. (2012). Teaching and learning at a distance: Foundations of distance education (5th ed.). Boston, MA: Pearson.

Sword, T. S. (2012). The transition to online teaching as experienced by nurse educators. Nursing Education Perspectives, 33(4), 269-71.

Thormann, J., \& Zimmerman, I. K. (2012). The complete step-by-step guide to designing and teaching online courses. New York, NY: Teachers College Press. 
Van de Vord, R., \& Pogue, K. (2012). Teaching time investment: Does on-line really take more time than face-to-face? International Review of Research in Open and Distance Learning, 13(3), 132-146.

Van Manen, M. (1997). Researching lived experience: Human science for an action sensitive pedagogy (2nd ed.). London, UK: The Althouse.

Whitelaw, C., Sears, M., \& Campbell, K. (2004). Transformative learning in a faculty professional development context. Journal of Transformative Education, 2, 9-27.

Yin, R. K. (2014). Case study research: Design and methods (5th ed.). Thousand Oaks, CA: Sage. 


\section{Appendix A}

\section{Part I: Demographic Information}

In this study, you will be identified by an alias. I will ask you nine questions about your demographic information.

Alias Name:

1. What is your gender? () Male () Female

2. What is your age range? () Under 20 () 20-29 () 30-39 () 40-49 () 50-59 () 60-69 () 70+

3. What is your faculty rank? () Adjunct Professor () Instructor () Assistant Professor () Associate Professor () Professor

4. How many years of teaching experience do you have at a Historically Black University?

5. How many years of teaching experience do you have total?

6. How many years of online teaching experience do you have?

7. What is your discipline and equivalent course taught?

8. What is your level of teaching? () Undergraduate () Graduate () Mixed

9. Do you use () Synchronous () Asynchronous () Both as a communication method?

\section{Part II: Experience Narrative}

Please describe in detail your experience based on questions 10-18:

10. Describe how teaching online changed your attitude and perspectives when you returned to face-to-face teaching?

11. Describe how your role and teaching practices altered when you returned to instruction in a face-to-face classroom?

12. Did you change your content in any way when you returned to the face-to-face classroom? 
13. What teaching methods and/or changes did you return to the face-to-face classroom with?

14. What communication strategies did you transfer from online to face-to-face teaching?

15. Has your Student-to-Faculty interaction and Student-to-Student interaction changed from online to face-to-face teaching? If yes, can you explain how?

16. What changes in face-to-face instructions can be attributed to the experience of online teaching?

17. Describe how professional development can assist online instructors, what topic would you include to improve the transitioning process for new instructors, and what additional training do you think you still need to assist with continuous improvement?

18. Do you have additional comments that you think would be beneficial to this study?

Thank you for your time. You will receive a transcript of the interview in about three weeks and you will have one week to review the transcript. When the study is complete, you will be given a copy of the results upon request. 